\title{
Conversão pessoal diante do Reino de Deus
}

\author{
Personal conversion towards the Kingdom of God
}

Vitor Galdino Feller

\section{Resumo}

O apelo para a conversão pessoal, tão presente em documentos eclesiopastorais, carece de concretude. Como acontece esta conversão? Sugere-se, neste artigo, que ela seja confrontada com a mensagem e prática do Reino de Deus pregado por Jesus de Nazaré, com sua exigência de conversão. $\mathrm{O}$ artigo propõe que as respostas que diferentes grupos deram à proposta de Jesus sejam paradigmáticas para os nossos tempos. Nesse sentido, retoma três diferentes atitudes em relação ao Reino: a dos pobres, destinatários naturais do Reino, que o acolhem com alegria; a dos discípulos, que são chamados a entender e aceitar a estratégia libertadora e conflitiva de Jesus no anúncio do Reino e a rejeição do antirreino, e que seguem Jesus até o fim; a das as autoridades religiosas e políticas, que, aprisionadas nos mecanismos ativos da opressão, rejeitam o Reino. Por fim, o artigo desafia a todos os cristãos a se converterem ao Reino tal como foi pregado e vivido por Jesus.

Palavras-chave: Reino de Deus. Antirreino. Conversão pastoral. Atitudes ante o Reino.

\section{Abstract}

The call for personal conversion, present in many ecclesio-pastoral documents, lacks concreteness. How does this conversion happen? It is suggested, in this article, that it be confronted with the message and practice of the Kingdom of God preached by Jesus of Nazareth, with his demand for conversion. The article proposes that the responses that different groups gave 
to Jesus' proposal are paradigmatic for our times. In this sense, it resumes three different attitudes in relation to the Kingdom: that of the poor, natural receivers of the Kingdom, who welcome it with joy; that of the disciples, who are called to understand and accept Jesus' liberating and conflicting strategy in announcing the Kingdom and rejecting the anti-kingdom, and who follow Jesus to the end; that of the religious and political authorities, who, trapped in the active mechanisms of oppression, reject the Kingdom. Finally, the article challenges all Christians to convert to the Kingdom as it was preached and lived by Jesus.

Keywords: Kingdom of God. Anti-kingdom. Pastoral conversion. Attitudes towards the Kingdom.

\section{Introdução}

A expressão "conversão pessoal" tem se tornado corriqueira nas falas dos agentes de pastoral, nos planos e projetos de ação evangelizadora. No Documento de Aparecida é frequente aparecer junto com a locução "conversão pastoral". Considerando que o termo conversão implica em mudança de direção, de mentalidades, de práticas, essas expressões deveriam deixar claro o novo objetivo para onde se volta a direção, o critério de exigências que mudam as mentalidades e práticas. Isso nem sempre fica evidente. Fala-se de conversão em sentido geral; ou, numa linguagem algo abstrata, de "mudança de vida integral", 1 de conversão "para combater o pecado", "que nos faz participar do triunfo do Ressuscitado e inicia um caminho de transformação", ${ }^{3}$ que "requer que as comunidades eclesiais sejam comunidades de discípulos missionários ao redor de Jesus Cristo"; ${ }^{4}$ relaciona-se conversão "ao seguimento em uma comunidade eclesial e a um amadurecimento de fé na prática dos sacramentos, do serviço e da missão". ${ }^{5}$ Há, todavia, em Aparecida, uma frase de onde se pode extrair algo mais concreto: a conversão para o Reino, a partir do Reino. “A conversão pessoal desperta a capacidade de submeter tudo a serviço da

\footnotetext{
${ }^{1}$ DAp 226.

${ }^{2}$ DAp 175.

${ }^{3}$ DAp 351 .

${ }^{4}$ DAp 368.

${ }^{5}$ DAp 289.
} 
instauração do reino da vida". ${ }^{6} \mathrm{O}$ documento fala em reino da vida; pode-se ver aí algo mais, que aponta para a concretude do Reino de Deus, pregado e iniciado por Jesus de Nazaré.

Daqui surgem perguntas: Por que a boa notícia desse Reino exige conversão, mudança de mentalidade e prática? Em que medida o Reino de Deus, núcleo da mensagem e da prática de Jesus, é o critério que verifica e qualifica a conversão pessoal dos fiéis? Os atuais seguidores de Jesus são de fato convertidos ao Reino? A adesão ao Reino de Deus é, também hoje, a verdadeira medida de engajamento no movimento de Jesus, de seguimento de sua práxis e missão?

O Reino de Deus, anunciado e iniciado por Jesus de Nazaré, é ofertado gratuitamente a todos. É o Evangelho de Deus, "não é um discurso meramente informativo, mas 'performativo', não simples comunicação, mas ação, força eficaz que entra no mundo para curar e transformar". ' Diante dele todos são convidados a converterem-se, a fim de poderem entrar nele e gozarem de sua felicidade. Oferta da graça, o Reino exige, contudo, conversão. "O Reino de Deus está próximo. Convertei-vos e crede na Boa Nova” (Mc 1,15).

Para compreender a conversão pastoral, da qual tanto se fala nos discursos e documentos da Igreja, sugere-se considerar as respostas que os diferentes grupos deram à proposta de Jesus, vendo-as como paradigmáticas para os nossos tempos. Os pobres, destinatários naturais do Reino, o acolhem com alegria. Os discípulos, chamados a entender e aceitar a estratégia libertadora e conflitiva de Jesus no anúncio do Reino e a rejeição do antirreino, seguem Jesus até o fim. As autoridades religiosas e políticas, aprisionadas nos mecanismos ativos da opressão, rejeitam o Reino. Diante dessas diferentes respostas, somos hoje interpelados à verdadeira conversão ao Reino, tornando-nos dispostos a pregá-lo e a vivenciá-lo do mesmo modo como Jesus.

\section{A conversão dos destinatários do Reino: alegre acolhida}

Dos pobres, doentes, pecadores, mulheres, que não eram bem vistos pela religião oficial e pela sociedade política, Jesus pediu a acolhida alegre do anúncio do que o Reino iria fazer em favor deles. ${ }^{8} \mathrm{O}$ Reino lhes foi anunciado com gratuidade, "não é um mérito deles, e menos ainda a consequência de um

${ }^{6}$ DAp 366.

${ }^{7}$ RATZINGER, J. / BENTO XVI, PP., Jesus de Nazaré, p. 58.

${ }^{8}$ SEGUNDO, J. L., O homem de hoje diante de Jesus de Nazaré, p. 161-183. 
valor que a pobreza teria". ${ }^{9}$ Não havia condição ou exigência para entrar no Reino a não ser a acolhida alegre e a tomada de consciência de sua miséria, de sua própria dignidade de filhos de Deus, de sua condição de destinatários e sujeitos do projeto divino em favor da vida para todos, a começar dos últimos. Eram destinatários privilegiados do Reino, ${ }^{10}$ não por serem moralmente bons ou possuidores de determinadas qualidades subjetivas, mas simplesmente por serem necessitados. E porque o amor de Deus é essencialmente compassivo, “porque Deus é 'humano', porque não pode aguentar essa situação e vem para cumprir sua vontade sobre a terra: que a pobreza cesse sua obra destruidora de humanidade". ${ }^{11}$ Deus chega com poder para governar e irá fazê-lo provocando reversão da atual situação de miséria e sofrimento do povo. "No Reino que ele há de estabelecer, recompensará os que sofrem injustamente neste mundo". ${ }^{12}$

Sendo primeiramente destinatários do Reino, em vista de sua própria humanidade, os pobres também foram chamados a serem sujeitos do Reino. De fato, Jesus aproveitou todas as ocasiões a sua disposição para tornar sujeitos conscientes do anúncio do Reino todos aqueles que foram tocados por sua obra salvífico-libertadora, que chegava gratuitamente aos que dela necessitavam. Tocados em primeira mão pelos sinais do Reino, ${ }^{13}$ podiam experimentar a proximidade e a presença de Deus e de sua misericórdia, "a realeza de Deus sobre o mundo, a qual de um modo novo se torna acontecimento na história". ${ }^{14}$ De descrentes que eram de sua própria dignidade, tornavam-se mensageiros da maravilhosa boa nova do Reino, que acontecia em sua própria história.

Nas parábolas do Reino e em outros ensinamentos, como as bemaventuranças, por exemplo, Jesus lhes anuncia a proximidade e a certeza da vinda do Reino, na alegria incondicionada que se aproxima dos que têm tanta necessidade de paz e esperança. "Os pobres definem o Reino porque serão seus possuidores. Para eles é que ele vem. A ponto de que aqueles que estão em situação oposta deverão responder logicamente ao anúncio de sua chegada com um ai! de dolorosa surpresa". ${ }^{15}$

Também hoje os discípulos missionários de Jesus são convocados ao

\footnotetext{
${ }_{9}^{9}$ SEGUNDO, J. L., O homem de hoje diante de Jesus de Nazaré, p. 164.

${ }^{10}$ BATTAGLIA, V., Gesù Cristo luce del mondo, p. 95-99.

${ }^{11}$ SEGUNDO, J. L., O homem de hoje diante de Jesus de Nazaré, p. 164.

${ }^{12}$ MEIER, J. P., Um judeu marginal, v. II / 2, p. 136.

${ }^{13}$ MOINGT, J., Deus que vem ao homem, v. 1, p. 299-300.

${ }^{14}$ RATZINGER, J. / BENTO XVI, PP., Jesus de Nazaré, p. 64.

${ }^{15}$ SEGUNDO, J. L., O homem de hoje diante de Jesus de Nazaré, p. 164.
} 
anúncio messiânico do Reino e à denúncia profética do antirreino, tornandose solidários com os pobres, pecadores, doentes, dos que sofrem nas periferias geográficas e existenciais, "seja qual for a situação moral ou pessoal em que se encontrem", ${ }^{16}$ vendo neles a carne de Cristo, e, de outra parte, denunciando a idolatria do mercado, a globalização excludente, que marginaliza esses mesmos pobres. ${ }^{17}$

No anúncio querigmático do Reino de Deus, como seu sacramento, germe e instrumento, a Igreja é chamada a continuar a obra taumatúrgica e didática de Jesus, que, em tudo o que fez e disse, foi sempre uma boa notícia para os pobres. Nosso compromisso com o Reino de Deus nos leva a fixar o olhar naqueles que seriam hoje os escolhidos de Jesus como primeiros destinatários do anúncio do Reino. Para evangelizar do jeito de Jesus de Nazaré, a Igreja deve escolhê-los também como prioridade em seus projetos e agendas. Eles são hoje não somente os destinatários, mas os primeiros e principais sujeitos do Reino de Deus.

Desde Medellín, os documentos do episcopado latino-americano vêm atualizando a lista dos pobres e sofredores e excluídos nos quais somos chamados a ver e amar o rosto do próprio Cristo. A lista é enorme: famintos, migrantes, vítimas do narcotráfico e do tráfico de pessoas, refugiados de guerras e de catástrofes climáticas, migrantes que não encontram acolhida, desaparecidos, doentes, toxicodependentes, idosos desamparados, menores abandonados, crianças vítimas da exploração sexual, da pornografia e do trabalho infantil, mulheres maltratadas, desempregados, pessoas que vivem na rua das grandes cidades, indígenas e afro-americanos, agricultores sem terra. ${ }^{18}$ Nesses rostos de excluídos, além de vermos o rosto do Cristo sofredor, vemos também o rosto das multidões, de pobres e pecadores, de doentes e endemoninhados, de mulheres e estrangeiros, aos quais Jesus anunciou preferencialmente o Reino. A eles cabe-nos hoje anunciar gratuitamente a boa notícia do Reino de Deus, pedindo-lhes unicamente que se conscientizem de sua dignidade e acolham, com alegria, a compaixão misericordiosa do Pai, revelada nas palavras e ações dos discípulos missionários de seu Filho Jesus Cristo. Nessa acolhida alegre e incondicional, já estarão, também eles, entrando na dinâmica do Reino e comprometendo-se com seu anúncio e manifestação do mundo atual.

\footnotetext{
${ }^{16}$ DP 1142.

${ }^{17}$ EG 53-58.

${ }^{18}$ DM, Justiça; DP 31-39; DSD 178; DAp 402.
} 
Trata-se aqui da opção pelos pobres, que é "mais uma categoria teológica que cultural, sociológica, política ou filosófica", ${ }^{19}$ impulsionada na prática pastoral da América Latina, a partir das indicações do Concílio Vaticano II, que propôs à Igreja seguir o caminho da pobreza e da perseguição de seu fundador, reconhecendo-o e servindo-o nos pobres, com o intento de aliviarlhes as necessidades. ${ }^{20}$

$\mathrm{Na}$ conferência de Puebla, a Igreja latino-americana explicitou essa página do Concílio nestes termos:

A Conferência de Puebla volta a assumir [...] uma clara e profética opção preferencial e solidária pelos pobres, não obstante os desvios e interpretações com que alguns desvirtuaram o espírito de Medellín, e o desconhecimento e até mesmo a hostilidade de outros. Afirmamos a necessidade de conversão de toda a Igreja para uma opção preferencial pelos pobres, no intuito de sua integral libertação. ${ }^{21}$

Desde então o magistério pontifício também assumiu essa proposição para a Igreja em todo o mundo. João Paulo II afirmou que fez sua a opção pelos pobres, tornando-a preocupação central de sua ação pastoral, "já que esta é a eterna mensagem do Evangelho: assim o fez Cristo, assim fizeram os apóstolos, assim fez a Igreja no decurso de sua história duas vezes milenar". ${ }^{22}$

Diante dos pobres deste mundo, para ser fiel ao seu Senhor, a Igreja deve estar em comunhão com os pobres e constituir-se de comunidades que vivam a pobreza, de modo a "sacudir a todos para que estejam despertos, para compreenderem a propriedade apenas como serviço, para contraporem à cultura do ter uma cultura da liberdade interior e assim criarem os pressupostos para a justiça social". ${ }^{23}$ No discurso de abertura dos trabalhos da Conferência de Aparecida, Bento XVI afirma: "A opção preferencial pelos pobres está implícita na fé cristológica naquele Deus que se fez pobre por nós, para enriquecer-nos com sua pobreza (2Cor 8,9$)$ ". ${ }^{24}$

\footnotetext{
${ }^{19} \mathrm{EG} 198$.

${ }^{20}$ LG 8.

${ }^{21}$ DP 1134.

22 JOÃO PAULO II, PP., Discorso di Giovanni Paolo II ai cardinali, ai membri della famiglia pontificia e alla curia romana

${ }^{23}$ RATZINGER, J. / BENTO XVI, PP., Jesus de Nazaré, p. 81.

${ }^{24}$ BENTO XVI, PP., Discurso na sessão inaugural da V Conferência-Geral do Episcopado da América Latina e do Caribe, p. 65.
} 
E o Papa Francisco insiste que o núcleo da ação evangelizadora é ver e amar Cristo na carne dos pobres, emprestando-lhes a nossa voz nas suas causas, sendo seus amigos, escutando-os e acolhendo "a misteriosa sabedoria que Deus nos quer comunicar através deles". 25

\section{A conversão dos colaboradores do Reino: profetismo martirial}

Dos seus discípulos e seguidores e colaboradores, que fizeram opção pelo Reino, em princípio até as últimas consequências, Jesus exigiu as qualidades próprias da missão. Qualidades proféticas como o heroísmo e a entrega da própria vida, no enfrentamento dos conflitos advindos dessa missão. Jesus ajudou-os a compreender os mecanismos do aparelho ideológico e religioso que ocasionava opressão dentro de Israel. Levou-os a distinguir entre a concepção libertadora da revelação divina em oposição à outra concepção de revelação, própria das autoridades político-religiosas, que eram fonte de opressão. Jesus abriu-lhes a mente para o entendimento de sua teologia global, anti-ideológica, em sua oposição à teologia do status quo dos fariseus, escribas e doutores da lei e dos sacerdotes do Templo. Por isso, "advertia seus discípulos que hostilidade e perigos poderiam estar reservados a eles no futuro, assim como a ele próprio". ${ }^{26}$

Fundamento para essa mudança de mentalidade e de nova compreensão da religião e de sua dimensão sócio-política foi a conversão para Deus. ${ }^{27}$ Os discípulos de Jesus foram chamados a fazer a experiência de um Deus que é Pai, ao mesmo tempo bom e exigente.

Com esse Deus que é bom Jesus tem uma relação de extrema confiança e ensina os discípulos a se abandonarem ao amor desse Deus que é Pai. Apresenta-o como Deus da misericórdia, do perdão, da ternura (Lc 3,36; 15,1132). Um Deus à mercê dos seres humanos. Um Deus a quem se chega não pelo poder, mas pelo amor. O Deus de Jesus não é autoritário e opressor, como o apresentavam o legalismo dos fariseus e o sacrificialismo dos sacerdotes. Por seus gestos de carinho e bondade para com os pobres e doentes, para com os excluídos da religião e da sociedade, Jesus é o proto-sacramento desse Deus compassivo e indulgente. As multidões, que se sentiam afastadas de Deus, por não conseguirem dar conta de todos os preceitos impostos pelos donos da

${ }^{25}$ EG 198.

${ }^{26}$ MEIER, J. P., Um judeu marginal, v. III / 1, p. 70.

${ }^{27}$ SOBRINO, J., Jesus, o libertador, p. 202-284; CASTILLO, J. M., Jesus, p. 105-130; 170-223. 
religião, viam em Jesus a visita e a aproximação de Deus $(\operatorname{Lc} 7,16)$. Diante desse Deus os discípulos foram se entregando ao seguimento de Jesus e à acolhida de sua proposta: o Reino de Deus, Reino de vida em abundância para todos (Jo 10,10).

Os discípulos também aprenderam que, para Jesus de Nazaré, Deus-Pai é exigente. A bondade e aproximação de Deus não impediam que Jesus o experimentasse também como um Deus transcendente, totalmente outro e, por isso, exigente. ${ }^{28}$ Um Deus diante do qual Jesus está disponível, numa entrega incondicional, vivendo sua humanidade concreta. Um Deus que não se deixa enredar e manipular pelas mediações humanas da lei e do sacrifício, como o imaginavam os fariseus e sacerdotes. Não um Deus à mão do ser humano, mediado pelo poder terreno da religião e da política, mas um Deus totalmente outro. Primeira e fundamental exigência que Deus transcendente e totalmente outro faz a Jesus e, por consequência, aos discípulos, é a da convergência total para com seu projeto: Jesus e os discípulos devem buscar sempre a vontade de Deus, escolher sempre o bem concreto que Deus pede a cada momento. Jesus e os discípulos têm que deixar Deus ser Deus, não podem manipular a Deus a seu bel-prazer, mas devem deixar-se guiar por Deus.

Assim, vendo em Jesus alguém totalmente convertido e convergido para o Pai, Deus bom e exigente, os discípulos são interpelados à conversão religiosa ao Deus do Reino, são impelidos ao primado de Deus, a pôr Deus em primeiro lugar, a buscar antes de tudo o Reino de Deus e sua justiça (Mt 6,33).

Assim convertidos a Deus e ao seu Reino, a eles foi confiado o mistério do Reino de Deus (Mt 13,11; Mc 4,11), que, por sua vez, só podia ser percebido na contradição do antirreino proposto e realizado pelos chefes político-religiosos. O discipulado de Jesus não se concebia sem a compreensão global desse conflito básico. O discipulado implicava em conhecer e enfrentar o fermento dos fariseus e saduceus e herodianos, metáfora para o conceito de ideologia opressora. Os discípulos precisavam das qualidades do próprio Jesus. "Qualidades proféticas, com toda a clarividência, heroísmo e entrega que o profetismo implica, e que implicou de modo particular Jesus, por causa do conflito que essa missão gera com interesses não menos urgentes por estarem disfarçados". ${ }^{29}$ Associando os discípulos à tarefa de anunciar o Reino, a bondade do Pai, a confiança no Pai, Jesus também lhes confiava a tarefa

\footnotetext{
${ }^{28}$ LOHFINK, G., Jesus de Nazaré, p. 282-298.

${ }^{29}$ SEGUNDO, J. L., O homem de hoje diante de Jesus de Nazaré, p. 212.
} 
de desmantelar os mecanismos da opressão ideológico-político-religiosa do antirreino.

Tratava-se de uma nova imagem do ser de Deus e, correlativamente, uma nova percepção do agir de Deus, a prática do Reino e a denúncia do antirreino. Um Deus compassivo e comprometido com os que sofrem, "um Deus 'obrigado' por fidelidade a si mesmo a lutar contra a ideologia que instrumentaliza a lei religiosa como arma de opressão", ${ }^{30}$ um "Deus (que) se considera responsável pelo êxito de sua criação, que está associado à plena humanização dos homens à sua semelhança, que é ao mesmo tempo a condição e o fruto de sua adoção filial por Deus". ${ }^{31}$ Tratava-se de uma ação ao mesmo tempo política e religiosa: "a uma nova 'política' corresponde uma nova noção de Deus. À medida que Jesus põe em prática a estratégia do Reino de Deus, aparecem novas facetas do rosto divino". ${ }^{2}$ Jesus foi tanto mais político na prática (o agir do Reino), quanto mais religiosa era sua pregação (o ser de Deus). Tratava-se de uma opção clara: "Ninguém pode servir a dois senhores (...) Não podeis servir a Deus e ao Dinheiro" (Lc 16,13). Jesus incorporou os discípulos a uma tarefa perigosa, tal como a sua própria, que poderia terminar no desenlace lógico do conflito produzido por sua pregação e práxis, o destino de morte.

Os atuais seguidores de Jesus também são chamados ao anúncio querigmático do Reino de Deus tendo consciência dos conflitos a serem enfrentados, assumindo decididamente o profetismo crítico diante das maldades produzidas pelos poderes do mundo e dispondo-se a ter o mesmo destino trágico do Mestre.

O Documento de Aparecida interpela os discípulos missionários a seguirem o Mestre assumindo seu estilo de vida: a obediência ao Pai, a prática das bem-aventuranças, a compaixão diante da dor humana, a proximidade aos pobres e aos pequenos, a fidelidade à missão, o amor serviçal até à doação da vida. ${ }^{33}$ E conclui: "Identificar-se com Jesus Cristo é também compartilhar seu destino". ${ }^{34}$

${ }^{30}$ SEGUNDO, J. L., O homem de hoje diante de Jesus de Nazaré, p. 183.

${ }^{31}$ MOINGT, J., Deus que vem ao homem, v. 2, p. 431.

${ }^{32}$ SEGUNDO, J. L., O homem de hoje diante de Jesus de Nazaré, p. 183.

${ }^{33}$ DAp 139-140.

${ }^{34}$ DAp 140. 


\section{A conversão das autoridades religiosas: deslocamento radical}

Há uma exigência maior de radical mudança de mentalidade, que Jesus faz ao grupo dos chefes religiosos, àqueles que definiam oficialmente qual era a vontade de Deus. ${ }^{35}$ Deveriam passar de uma segurança opressora da letra à insegurança libertadora da opção pela dinâmica do Reino. Deveriam passar da interpretação da lei na base de princípios abstratos para a interpretação a partir de dados concretos da vida. ${ }^{36}$ Jesus exigiu nova hermenêutica. Só a sintonia com os preferidos do Reino, pobres, doentes, estrangeiros e marginalizados da religião oficial e da sociedade excludente, é que abriria o coração dos chefes religiosos à interpretação correta de Deus, da lei e dos profetas e da própria mensagem de Jesus, do Reino de Deus que ele pregava.

Numa atitude conflitiva e perigosa, Jesus assumiu o enfrentamento do poder religioso, ideológico e político, o que o levou a tornar-se mártir do Reino. ${ }^{37} \mathrm{O}$ movimento de Jesus teve que haver-se com grupos que competiam pela "aceitação e adesão do povo de Israel, ou, em outros termos, pelo poder, autoridade ou influência necessários para governar Israel", os fariseus, os saduceus, os essênios e os zelotas, contra os quais Jesus se posicionou por formas marcadamente diferentes. ${ }^{38}$ Jesus desmascarou os que se identificavam falsamente com a Lei (legalismo), com normas religiosas, e que não viviam em nome do mistério que se deveria expressar nas normas. Jesus desmantelou sistematicamente, por meio de parábolas polêmicas e de controvérsias teológicas, a ideologia religiosa mantida por eles. A estratégia global de Jesus desmontou o mecanismo ideológico com que os próprios pobres faziam da religião que praticavam um instrumento de opressão em benefício dos poderosos de Israel. A polêmica de Jesus contra as autoridades religiosas de Israel adquiria radicalidade maior: desmontando o mecanismo de opressão que exerciam, Jesus os acusava de servirem-se do poder religioso para proveito próprio. A conversão exigida das autoridades pela pregação e práxis do Reino implicava em "passar da segurança (opressora) da letra à insegurança (libertadora) do ter que optar pelos pobres. Só a sintonia com estes e com seus interesses abrirá o coração à interpretação correta de

\footnotetext{
${ }^{35}$ SEGUNDO, J. L., O homem de hoje diante de Jesus de Nazaré, p. 186-207.

${ }^{36}$ Por exemplo, em Mc 3,1-5, estava em jogo, de um lado, o princípio do sábado e, de outro, a vida do paralítico.

${ }^{37}$ PAGOLA, J. A., Jesus, p. 399-484.

${ }^{38}$ MEIER, J. P., Um judeu marginal, v. II / 2, p. 354.
} 
Deus". ${ }^{39}$ Assim, a crítica de Jesus aos chefes religiosos e políticos pretendia abrir a autoridade, manipulada por eles, à dimensão da pertença a Deus.

Isso vale também hoje para as autoridades da Igreja - ministros ordenados, lideranças leigas, coordenadores das diversas pastorais e movimentos. Sob o ponto de vista da fé, a autoridade na Igreja hoje é continuidade real da missão que Jesus recebeu do Pai (Lc 10,16). Jesus elevou esta autoridade-serviço ao assumi-la em sua intimidade com o Pai ("como o Pai me enviou, eu vos envio", Jo 20,21). Nesta autoridade, que nunca pode ser autoritarismo (pois não é autoridade própria, mas recebida de Cristo), a Igreja toda, também os ministros, devem ser ouvintes e servidores desta sua origem. A autoridade da Igreja constitui-se em ser anunciadora da esperança para todos, em primeiro lugar aos mais desesperados, seja em termos sociológicos seja em termos existenciais.

Nesse sentido, será preciso insistir na conversão das autoridades religiosas. Muitos pensam que não se pode repetir hoje o que acontecia no tempo de Jesus. Supõe-se, erradamente, que a Igreja, por sua transcendência e missão reconciliadora, não exerça nenhum papel de exclusão, opressão e violência. $O$ pecado dessas autoridades é tanto maior quanto mais se consideram justos e sem necessidade de conversão. Esse pecado é um crime religioso pois, em nome de Deus a autoridade é exercida para criar uma relação de indiferença e exclusão com os fracos e pequenos, pobres e pecadores. Desse modo, as autoridades religiosas tornam-se, então, também hoje, pecadores imperdoáveis, já que a justiça que creem possuir lhes fecha o caminho de uma possível conversão. O perdão de Deus só será possível na medida em que se converterem à nova hermenêutica: interpretar as leis de Deus a partir de ações em favor dos necessitados.

Não se trata, é claro, de entender esta "nova hermenêutica" no sentido de analisar o conteúdo evangélico só a partir da práxis, com o risco de diminuir a força do chamado de Jesus Cristo. Por isso, a conversão das autoridades religiosas se deve dar não só em nome de uma nova hermenêutica, mas, sobretudo, em nome da radicalidade da pertença de qualquer autoridade à fonte da revelação, o próprio Deus. A Igreja inteira é de Cristo; qualquer autoridade na Igreja é exercida a partir dele e em nome dele. A partir daqui se opera uma visão realmente libertada da autoridade,

${ }^{39}$ SEGUNDO, J. L., O homem de hoje diante de Jesus de Nazaré, p. 204. 
no sentido da descoberta da origem da fé, inclusive da autoridade que não é do ser humano, mas de Jesus Cristo.

A crítica recorrente que o Papa Francisco faz a respeito do clericalismo e do carreirismo de muitos clérigos põe-se na esteira da crítica de Jesus aos chefes religiosos do seu tempo. O Papa adverte que corre-se hoje o risco do mundanismo espiritual. $\mathrm{O}$ clérigo mundano é apegado à segurança doutrinal ou disciplinar que dá lugar a um elitismo narcisista e autoritário; analisa e classifica os demais, em vez de lhes facilitar o acesso à graça; pretende dominar o espaço da Igreja; tem um cuidado exibicionista da liturgia, da doutrina e do prestígio da Igreja, mas não se preocupa com a real inserção do Evangelho na vida concreta do povo; transforma a vida da Igreja numa peça de museu ou numa posse de poucos; é fascinado pelo poder, quer mostrar conquistas sociais e políticas; é atraído pelas dinâmicas de autoestima e de realização autorreferencial; deixa-se envolver numa densa vida social cheia de viagens, reuniões, jantares, recepções; desdobra-se num funcionalismo empresarial, carregado de estatísticas, planificações e avaliações, onde o principal beneficiário não é o povo de Deus, mas a Igreja como organização; encerrase em grupos de elite, não sai realmente à procura dos que estão sedentos de Cristo. ${ }^{40}$ Segundo o Evangelho de João, o "mundo" é aquilo que não vive segundo a vontade do Pai, não aceita o ensinamento nem o exemplo de Jesus. O clero mundano é aquele que não vive a alegria das bem-aventuranças, que, portanto, não tem o coração livre para Deus e não é luz para outras vidas, não está comprometido, em nome do Evangelho, com os pequenos e últimos, não se abre ao Reino de Deus proposto por Jesus de Nazaré.

$\mathrm{O}$ anúncio querigmático do Reino de Deus passa pela conversão das autoridades religiosas. Uma conversão que passa pela razão e pelo coração. Pela razão, por meio de uma nova hermenêutica que dê capacidade para entender os valores do Reino em sua oposição aos valores do mundo, para diferenciar a lógica de Deus, fundada no amor a todos, da lógica do mundo, do mercado, da moda, da mídia, fundada na exclusão das maiorias e das minorias. Uma conversão que diga não à idolatria do mercado e à economia que mata. ${ }^{41}$ Que passa também pelo coração, por meio de uma verdadeira mudança de atitudes e agendas, com prioridades existenciais e efetivas em favor do projeto de Deus. O convite do Papa Francisco, a buscar uma Igreja pobre, com os

\footnotetext{
${ }^{40}$ EG 93-97.

${ }^{41}$ EG 53-58.
} 
pobres e para os pobres, põe-se na linha do ensinamento de Jesus. "Este é, sem dúvida, um dos primeiros sinais com que a comunidade cristã se apresentou no palco do mundo: o serviço aos mais pobres". ${ }^{42}$

As autoridades religiosas são interpeladas a assumir para si a crítica do cardeal Ratzinger acerca da sujeira na Igreja. Certamente não só a sujeira da pedofilia, como se costuma interpretá-la, mas de sua verdadeira causa: o uso perverso da autoridade. "Quão pouca fé existe em tantas teorias, quantas palavras vazias! Quanta sujeira há na Igreja, e precisamente entre aqueles que, no sacerdócio, deveriam pertencer completamente a ele! Quanta soberba, quanta autossuficiência!"’33

\section{A conversão de todos}

Todos na Igreja são chamados à conversão, a fim de poderem acolher e anunciar o Reino. A Igreja existe para evangelizar. Ela nasceu do anúncio da boa notícia da libertação integral do ser humano e da sua elevação à vida divina. Vive desse anúncio e para esse anúncio. Para pôr-se ao serviço do Reino e, desse modo, indicar a todos o Reino na sua plenitude eterna, a Igreja se serve de muitos meios. Entre eles, o anúncio da Palavra, os sacramentos, que encontram seu ápice na Eucaristia, a oração, a religiosidade popular, as ações caritativas, meios que, embora possam adquirir manifestações de ordem política, econômica ou social, são, em sua interioridade e inteireza, de natureza religiosa e sobrenatural.

No entanto, em vez de tornar-se sempre e cada vez mais uma Igreja em saída, sempre disponível à evangelização, a ser germe, sinal e instrumento do Reino, deixa-se por vezes cair na tentação da acomodação às estruturas do mundo, "uma Igreja satisfeita consigo mesma, que se acomoda neste mundo, que é autossuficiente e se adapta aos critérios do mundo", uma Igreja que dá "à organização e à institucionalização uma importância maior do que dá ao seu chamamento a permanecer aberta a Deus e a abrir o mundo ao próximo". ${ }^{44}$

Anunciar Jesus é falar de seu Reino. O anúncio do Reino de Deus está de tal modo no centro da missão de Jesus que ele mesmo é a Boa-Nova. Há nele, no dizer de João Paulo II, "identidade entre mensagem e mensageiro,

\footnotetext{
${ }^{42}$ FRANCISCO, PP., Mensagem do Santo Padre Francisco para o $1^{\circ}$. Dia Mundial dos Pobres.

${ }^{43}$ RATZINGER, J., Pregação na IX Estação da Via-Sacra da Sexta-feira Santa de 2005.

${ }^{44}$ BENTO XVI, PP., Discurso no Encontro com os Católicos Comprometidos na Igreja e na Sociedade.
} 
entre o dizer, o fazer e o ser [...], total identificação com a mensagem que anuncia: proclama a 'Boa Nova' não só por aquilo que diz ou faz, mas também pelo que é". ${ }^{45}$

Ao pregar a pessoa e o querigma de Jesus Cristo, a Igreja deve pregar o Reino que ele pregou e iniciou. A Igreja de nossos tempos deve voltar às fontes para, na imitação e no seguimento de seu Mestre, retomar de modo claro a pregação do Reino de Deus para todas as pessoas e todos os povos. Segundo Paulo VI, "aqueles que acolhem com sinceridade a Boa Nova [...] reúnem-se, portanto, em nome de Jesus para conjuntamente buscarem o Reino, para o edificar e para o viver [...] A Boa Nova do Reino que vem e que já começou, de resto, é para todos os homens de todos os tempos". ${ }^{46}$

Esperança e espera pelo Reino que vem e coragem para superar as provações enquanto ele não chega à sua plenitude. O que viveram os judeus antes de Cristo, cabe agora aos convertidos à mensagem do Senhor. Não se pode esquecer que "essa espera [...] é a marca de uma esperança invencível no futuro, e que ela nasceu da coragem com que esse povo (judeu) superou [...] inúmeras provas tão cruéis". ${ }^{47}$

\section{Conclusão}

O anúncio e a prática do Reino de Deus por Jesus de Nazaré afetaram positivamente a vida de muitas pessoas. Cegos, surdos e paralíticos receberam a cura, leprosos foram purificados, mortos foram reanimados, aos pobres foi anunciado o Evangelho, ricos descobriram o caminho da partilha e da solidariedade, famintos se saciaram, pecadores foram acolhidos com misericórdia e perdão, mulheres foram incluídas na prática religiosa. Foram muitos os que não se escandalizaram da missão messiânica e profética de Jesus (Lc 7,21-23) e encontraram nele o sentido de sua vida.

Muitos dos que foram afetados positivamente se tornaram seus discípulos. Além dos apóstolos, muitos homens e mulheres passaram a fazer parte do movimento messiânico de Jesus. Constituíram-se membros da Igreja primitiva, saíram pelo mundo a pregar a Boa Nova do Reino. Sofreram incompreensões, calúnias, perseguições e até o martírio na fidelidade ao Reino.

\footnotetext{
${ }^{45} \mathrm{RM} 13$.

${ }^{46} \mathrm{EN} 13$.

${ }^{47}$ MOINGT, J., O homem que vinha de Deus, p. 274 (parêntesis meu).
} 
Muitas pessoas, porém, foram afetadas negativamente pelo Reino, por resistirem à sua compreensão e acolhida. Fariseus, escribas e doutores da Lei fecharam-se em sua interpretação legalista da Lei, o jovem rico agarrouse a seus bens terrenos, sacerdotes do Templo permaneceram rígidos em sua insistência nos sacrifícios como meio de encontro com Deus em vista da pureza ritual, chefes políticos como Herodes e Pilatos mantiveram-se apegados a seu poder, soldados romanos permaneceram fiéis a seus chefes na linha da execução dos que ousassem afrontar o poder.

Vimos que a conversão pessoal, de que tanto se fala na linguagem eclesiopastoral dos últimos tempos, implica uma adesão ao Reino. Diferentemente dos chefes religiosos e políticos, que permaneceram fechados em suas mentalidades, posições e práticas religioso-idolátricas, a conversão pessoal implica a acolhida jubilosa do Reino, o engajamento em seu anúncio messiânico e a coragem da denúncia profética do antirreino, com correspondente mudança de interesses e práticas.

Pode-se dizer, então, que a conversão pessoal "desperta a capacidade de submeter tudo a serviço da instauração do reino da vida", ${ }^{48}$ enquanto aponta para a concretude do Reino de Deus, pregado e iniciado por Jesus de Nazaré. Trata-se da conversão para o Reino, a partir do Reino. Trata-se de pregar e viver o Reino do mesmo modo como Jesus.

\section{Referências bibliográficas}

BATTAGLIA, V. Gesù Cristo luce del mondo. Manuale di cristologia. Roma: Antonianum, 2013.

BENTO XVI, PP. Discurso na sessão inaugural da V Conferência-Geral do Episcopado da América Latina e do Caribe. In: BENTO XVI, PP. Pronunciamentos do Papa Bento XVI no Brasil. Brasília: CNBB, 2007. p. 59-76.

BENTO XVI, PP. Discurso no Encontro com os Católicos Comprometidos na Igreja e na Sociedade. Konzerthaus de Friburgo, 25 de setembro de 2011, na visita apostólica à Alemanha. Disponível em: <https://w2.vatican. $\mathrm{va} /$ content/benedict-xvi/pt/speeches/2011/september/documents/hf_ben-xvi_ spe_20110925_catholics-freiburg.html>. Acesso em: 3 jan. 2020.

CASTILlO, J. M. Jesus. A humanização de Deus. Petrópolis: Vozes, 2015.

${ }^{48}$ DAp 366. 
CELAM. Documento de Aparecida. Brasília: CNBB; São Paulo: Paulinas / Paulus, 2007.

CELAM. Documento de Santo Domingo. Petrópolis: Vozes, 1992.

CELAM. Conclusões de Medellín. São Paulo: Paulinas, 1987.

CELAM. Puebla: Conclusões. São Paulo: Loyola, 1979.

CONCÍLIO VATICANO II. Constituição Dogmática Lumen Gentium. In: CONCÍLIO VATICANO II. Concílio Ecumênico Vaticano II. Documentos. Brasília: CNBB, 2018. p. 75-174.

FRANCISCO, PP. Exortação apostólica Evangelii Gaudium sobre o anúncio do Evangelho no mundo atual. São Paulo: Paulus / Loyola, 2013.

FRANCISCO, PP. Mensagem do Santo Padre Francisco para o $\mathbf{1}^{\circ}$. Dia Mundial dos Pobres. XXXIII Domingo do Tempo Comum (19 de novembro de 2017), n. 2. Disponível em: <http://w2.vatican.va/content/francesco/ pt/messages/poveri/documents/papa-francesco_20170613_messaggio-i-giornatamondiale-poveri-2017.html . Acesso em: 3 jan. 2020.

JOÃO PAULO II, PP. Carta Encíclica Redemptoris Missio sobre a validade permanente do mandato missionário. São Paulo: Paulinas, 1991.

JOÃO PAULO II, PP. Discorso di Giovanni Paolo II ai cardinali, ai membri della famiglia pontificia e alla curia romana, n. 9. Venerdì, 21 dicembre 1984. Disponível em: <http://www.vatican.va/content/john-paul-ii/it/ speeches/1984/december/documents/hf_jp-ii_spe_19841221_cardinali-curia -romana.html>. Acesso: 3 jan. 2020.

LOHFINK, G. Jesus de Nazaré. O que ele queria? Quem ele era? Petrópolis: Vozes, 2015.

MEIER, J. P. Um judeu marginal. Repensando o Jesus histórico. Rio de Janeiro: Imago, 1997. v. II/2.

MEIER, J. P. Um judeu marginal. Repensando o Jesus histórico. Rio de Janeiro: Imago, 2003. v. III/1.

MEIER, J.P. Um judeu marginal. Repensando o Jesus histórico. Rio de Janeiro: Imago, 2004. v. III/2.

MOINGT, J. Deus que vem ao homem. Do luto à revelação de Deus. São Paulo: Loyola, 2010. v. 1. 
MOINGT, J. Deus que vem ao homem. Da aparição ao nascimento de Deus. São Paulo: Loyola, 2010. v. 2.

MOINGT, J. O homem que vinha de Deus. São Paulo: Loyola, 2008.

PAGOLA, J. A. Jesus. Aproximação histórica. Petrópolis: Vozes, 2010.

PAULO VI, PP. Exortação Apostólica Evangelii Nuntiandi sobre a evangelização no mundo contemporâneo. Petrópolis: Vozes, 1979.

RATZINGER, J. Pregação na IX Estação da Via-Sacra da Sexta-feira Santa de 2005. Disponível em: $<$ http://www.vatican.va/news_services/liturgy/2005/ via_crucis/po/station_09.html>. Acesso em: 3 jan. 2020.

RATZINGER, J. / BENTO XVI, PP. Jesus de Nazaré. Do batismo no Jordão à transfiguração. São Paulo: Planeta, 2007.

SEGUNDO, J. L. O homem de hoje diante de Jesus de Nazaré. São Paulo: Paulinas, 1985. v. II/I.

SOBRINO, J. Jesus, o libertador. Petrópolis: Vozes, 1996. v. 1.

Vitor Galdino Feller

Doutor em Teologia pela Pontificia Università Gregoriana Docente de Teologia na Faculdade Católica de Santa Catarina Florianópolis / SC - Brasil E-mail: vitorfeller@arquifln.org.br 